\title{
Developing Post-Operative Nursing Care Standards for Patient's Undergoing Cystectomy for Cancer Patients
}

\author{
Shaimaa Abd El-Hameid Hussein, Ahmed Awad Sayed Salem, Amal Mohammed Ahmed \& Sahra Zaki Azer.
}

Head nurse at South Egypt Cancer Institute, Assiut University, Egypt.

Assistant Professor of Surgical Oncology, Faculty of Medicine, Assiut University, Egypt.

Assistant Professor of Medical.Surgical Faculty of Nursing, Aswan University, Egypt.

Lecturer of Adult Nursing Department, Faculty of Nursing, Assiut University, Egypt .

\begin{abstract}
Aims: To assess nurses knowledge and practice regarding cystectomy patients and develop postoperative nursing care standards for patients undergoing cystectomy at South Egypt Cancer Institute. Subject \& Methods Descriptive research design was utilized in this study. Sample: A convenient sample of (60) nurses male and female working in surgical oncology department. The tools were utilized for data collection includes the following: Nurse's knowledge questionnaire, Nurses practice observation checklist, and Construction of standard of nursing care: Post-operative nursing care standards. Results: The majority of nurses are female $(86.7 \%)$, more than half of nurses their age ranged from $20>30$ years $(71.7 \%)$, and had diploma of nursing (70.0\%). The majority of nurses are married $(80.0 \%)$ and no had attended training programs (80.0\%, $95.0 \%$ respectively). More than two third of nurses (55.0\%) years of experience from 5-10 years. Conclusions: Nurses` knowledge and practice regarding postoperative nursing care standards for patients undergoing cystectomy in surgical oncology department at South Egypt Cancer Institute are inadequate that necessitate developing nursing care standards for such group of patients. Recommendation: Nurses are needs for in-service training programs and refreshing courses to improve their knowledge which will reflect into their practice regarding postoperative nursing care standards while working with patients.
\end{abstract}

\section{Key Word: Cystectomy, Standards \& Nursing.}

\section{Introduction}

Bladder cancer is an uncontrolled abnormal growth and multiplication of cells in the urinary bladder which have broken free from the normal control mechanisms of the body. Bladder cancer like cancers of other organs has the ability to spread (metastasize) to other body parts including the lungs, bones, and liver. The most common type of bladder cancer begins in cells lining the inside of the bladder and is called transitional cell carcinoma (Kaufman, Shipley \& Feldman, 2009).

Signs and symptoms of bladder cancer frequently are blood in urine (hematuria) urine may appear dark yellow, bright red or cola colored. Or urine may appear normal, but blood may be detected in a microscopic examination of the urine, frequent urination, painful urination, back pain and pelvic pain. Different causes of cancer bladder such as; Changes in the genetic material (DNA) of bladder cells may play a role because smoking, a parasitic infection as (schistosomiasis urinary tract), radiation and chemical exposure (Potter, 2006).

The American Cancer Society's estimates for bladder cancer in the United States for 2014. About 74,690 new cases of bladder cancer diagnosed (about 56,390 in men and 18,300 in women). (American Cancer Society, 2014). About 15,580 deaths from bladder cancer (about 11,170 in men and 4,410 in women). (American Cancer Society, 2014). In Assiut, the number of patients who have bladder cancer (male and female) during the period 2013 to 2014 admitted to surgery department of south Egypt cancer institute was approximately 410 cases. (South Egypt Cancer Institute Records, 2014).

Cystectomy is the surgical removal of all or part of the bladder. It is used to treat bladder cancer that has spread into the bladder wall or to treat cancer that has come back (recurrent) (Berglund \& Herr, 2012).

The treatment options for bladder cancer depend on a number of factors, including the type and stage of the cancer, the overall health, and treatment preferences includes medical and surgical treatment. The major objectives of medical therapy are to reduce the incidence of acute episodes of bladder cancer pain by transurethral resection of bladder tumor alone, systemic chemotherapy, primary radiation therapy bladder-sparing multimodality therapy and partial cystectomy. Surgery is the treatment of choice for bladder cancer disease. The criterion standard for the treatment of patients with stage T2-T4 disease is radical cystoprostatectomy for men and anterior pelvic exonerations for women. Additionally, all patients should undergo bilateral pelvic 
lymphadenectomy and urinary diversion (Mohanty, 2007).

Potential complications of surgery include: excessive bleeding, surgical wound infection, thrombophlebitis, pneumonia, pulmonary embolism, and rectal injury, ureterocutoneous fistulas, other cardio circulatory and small Stomal complications to be monitored include: Death (necrosis) of stomal tissue. Caused by inadequate blood supply, Retraction (stoma is flush with the abdomen surface or has moved below it). Prolepses (stoma increases length above the surface of the abdomen). Stenosis often associated with infection around the stoma or scarring. Mild stenosis can be removed under local anesthesia. Severe stenosis may require surgery for reshaping the stoma. Parastomal hernia usually due to placement of the stoma where the abdominal wall is weak or creation of an overly large opening in the abdominal wall (Kluwer, 2009).

The nursing care of urostomy plays important role to prevent complications. We can focus on how to change the pouch, empty pouch, irrigate stoma, dealing with some problems that can happen with a stoma, instruct What types of foods can the patients eat after a stoma, and How can a stoma fit into their lifestyle (work, exercise, bathing, relationship, and travelling) (Thomson, 2011).

Standards of care are guidelines used to determine what a nurse should of care measure the degree of excellence in nursing care and describe a competent level of nursing care (Mc Mahon, 2011).

Nursing Standards of Care pertain to professional nursing activities that are demonstrated by the nurse through the nursing process. These involve assessment, diagnosis, outcome identification, planning implementation, and evaluation. The nursing process is the foundation of clinical decision making and encompasses all significant action taken by nurses in providing care to all consumers (Diana Cook, 2010).

The importance of care standards is that it promotes guides and directs professional nursing practice, important for self-assessment and evaluation of practice by employers, patient and other stakeholders, Provides nurses with a framework for developing competencies, and aids in developing a better understanding and respect for the various and complimentary roles that nurses have. Types of nursing care standards structure. Things we use, process, things we do, outcome and the result (McMahon, 2011).

\section{Significance of the study}

Through a period of several years of work in surgery department at South Egypt Cancer Institute the researcher observed that the patient's undergoing cystectomy needed a special nursing care to improve the patient's outcome.

So this study will help such group of patients who will get a great benefit to develop nursing care standards; further more, results of this study could be helpful for health professional's specialty nurses in planning and implementing nursing care standards for such a group of patients.

\section{Aim of the study}

The aims of this study were

- To assess nurses' knowledge and practice regarding post operative nursing care standards for patients undergoing cystectomy.

- To develop postoperative nursing care standards for patients undergoing cystectomy at south Egypt cancer institute.

\section{Operational definition}

Cystectomy: Cystectomy is the surgical removal of all or part of the bladder. It is used to treat bladder cancer that has spread into the bladder wall or to treat cancer that has come back (recurrent)

(Berglund \& Herr, 2012).

Postoperative nursing care standers

Standards may be defined as "a benchmark of achievement which is based on a desired level of excellence". Standards of care measure the degree of excellence in nursing care and describes a competent level of nursing care (Osborn et al., 2010).

\section{Subjects \& Methods}

The present study aimed to assess nurse's knowledge and practice regarding cystectomy patients and develop postoperative nursing care standards for patients undergoing cystectomy at south Egypt cancer institute.

\section{Research design}

Descriptive research design will be utilized to conduct this study

\section{Study variables}

The independent variable in this study is the suggested postoperative Nursing care standards while the dependent variables are knowledge and practice.

The study was portrayed under four main designs as follows

- Technical design.

- Operational design.

- Administrative design.

- Statistical design.

Technical design

It includes study setting, subjects, and tools of data collection. 


\section{Study setting}

The study was conducted in surgical oncology department at South Egypt Cancer Institute at Assuit University

\section{Study subjects}

A convenience sample of all available nurses about (60) male and female working in surgery department who are willing to participate in the study, it consist of (8) Bachelor's and (52) nurses.

Tools

The tool of the study was utilized for data collection includes the following:

\section{Tool I: Nurse's questionnaire}

This sheet was developed by the researcher based on current national and international literature to assess nurse's knowledge regarding cystectomy patients such as: definition of cystectomy, types, indications, complications, and post operative nursing care ....etc. In addition to some selected biosocial characteristics for nurses as nurse's name, age, sex, marital status, qualification and years of experience.

An Arabic structured interview questionnaire sheet for nurses:

\section{It included three parts}

Part I: Socio demographic data about the nurses such as: age, gender, qualification, years of experience, training course and number of abortion. It included 6 items (questions from 1 to 6 ).

Part II: Nurses' knowledge about cystectomy patients. It included 6 items

(questions

from 7 to 12).

Part III: Nurses' knowledge about nursing care after cystectomy. It included 14 items (questions from 13 to26).

\section{Scoring system}

Each complete answer was get score of (2) and incomplete answer was get score of (1) but unknown answer was get score of (0). Patient caregivers who scored $(70 \%)$ or more were considered as having "very good" knowledge. Those who scored (60 > $70 \%)$ were considered having "good" knowledge while those scored $(50>60 \%)$ were considered as having "pass" knowledge. Less than $(50 \%)$ were considered poor.

Tool II: Nurses practice post cystectomy patient observation checklist.

Observation checklist was developed by the researcher based on reviewing of literature to assess nurses' practice. It was include hand washing, vital signs, wound care, drain tube care, nasogastric tube care, catheter care, assessment, planning, implementation, evaluation; reporting, recording and instruction.

\section{It includes two parts}

Part I: Immediate post-operative practice it include assess patients respiratory function, assess patient's circulatory function, maintain thermoregulatory function, assess wound site, assessing invasive procedures, assess indwelling urinary catheter, teaching the patient to make stoma care, assessing patient's gastrointestinal function, Assess fluid intake and output and assess patient's level of comfort it include 10 items ( question from 1to10)

Part II: Routine post operative nursing care it include relieving phantom pain, helping the patient to resolve grieving, enhancing body image, promoting independent self care, monitoring and managing potential complication it include 5 items (question from 1to5)

\section{Scoring system}

Scoring was rated for four levels: not done gets a score of (0), not applicable gets score of (1), incorrect gets score of (2) and correct answer gets score of (3).Those who obtained less than (50\%) were considered having inadequate level of practice. More than $(50 \%)$ were considered having adequate level of practice.

Tool III: Construction of postoperative nursing care standard

Post-operative nursing care standards was developed by the researcher based on the review of relevant literatures according to nurse's knowledge and practice that can help nurses in provision of a safe and effective care for cystectomy patients. It was includes anatomy of urinary system and urinary bladder, definition of bladder and cancer bladder, types of cancer bladder, causes, high risk, signs and symptoms, diagnosis, treatment and post operative nursing care standers with patients undergoing cystectomy it is consists of :safe environment in surgical oncology department, ensure that infection control use right, standers of care pre operative in oncology department, operating room, continuous observation for patients undergoing cystectomy, health teaching and instruction for patients before hospital discharge.

\section{II- Operational design}

The operational design includes preparatory phase, face \& content validity, pilot study and ethical consideration.

\section{1) Preparatory phase}

It was included reviewing of current literature and different studies related to assess nurses knowledge and practice toward safe care for cystectomy patient.

\section{Tool testing and pilot study}

The content and validity was done by (5) experts in medical surgical nursing field and medical staff. Their opinions were elicited regarding the tool format layout, consistency and scoring system. The content of tools was tested regarding to knowledge accuracy, relevance, competence, understanding, applicability 
and easiness for administrative minor modification were required.

A pilot study was applied on $10 \%$ (6 nurses) of the studied nurses before starting data collection on 60 nurses, the aim of pilot study was to assess tools clarity and applicability, time needed for filling in the sheet, moreover, to identify problems that may be encountered during the actual data collection. Necessary modifications were done and nurses caregivers included in the pilot study were excluded from the study group.

\section{Implementation phase}

The interview questionnaire was filled by the researcher while the nurses were on duty; purpose of the study was explained prior to get the questions asked. Each nurse involved in the study was interviewed to answer the questions. Observation checklist for nurses carried out during the morning and afternoon shift.

\section{Ethical consideration}

- The researcher was explain to eligible nurses about the research.

- Nurses was advised of their right to withdraw from the study at any point.

- Nurses name was coded for data entry so that their names could not be identified.

\section{III- Administrative design}

An official approval letters was obtained from the Dean of faculty of Nursing at Assiut University; Head of surgical oncology department at South Egypt Cancer Institute and Director of the study of faculty of Nursing at Assiut University were setting before starting any data collection, with explanation for the study aim to obtain permission and cooperation for data collection.

\section{Data collection was carried out from}

The interview questionnaire was filed by researcher while nurses give care for cystectomy patient; purpose of the study was explained prior to get the questionnaire asked. Each nurses involved in the study was interviewed to answer the questionnaire. Sampling was started and completed within 6 month from April 2014 to August 2014.

\section{VI-Statistical design}

The data obtained were reviewed, prepared for computer entry, coded, analyzed and tabulated. Descriptive statistics (i.e., frequencies and percentages, mean and stander deviation) were done using computer program (SPSS) version (16). One Way ANOVA test used in relationship between knowledge and practice. It's considered significant when P. value less than (0.05).

\section{Limitation of the study}

A lot of barriers during collecting data concerning thesis about assessment of nurse's knowledge and practice related to postoperative cystectomy patients at South Egypt Cancer Institute. Barriers such as some nurses saying what is the benefit of this, and this was reflected on filling the evaluation sheet that makes us retain for them again, and some also neglect filling in forms. Filling in the observation checklist took along time because observation include immediate, routine and before discharge of Patients. Most nurses not understand what the meaning of standards so explaining took long time.

- Nurses asked about benefit of this questionnaire.

- Observation checklist took long time because observation includes three phases.

- Look of nurses' knowledge resolving nursing care standard. 


\section{Results}

Table (1): Distribution of the sociodemographic of nurses characteristics in the study sample $(n=60)$.

\begin{tabular}{|c|c|c|}
\hline Variable & No. $(n=60)$ & $\%$ \\
\hline \multicolumn{3}{|l|}{ 1-Gender } \\
\hline Male & 8 & 13.3 \\
\hline Female & 52 & 86.7 \\
\hline \multicolumn{3}{|l|}{ 2-Age } \\
\hline$<20$ & 8 & 13.3 \\
\hline $20>30$ & 43 & 71.7 \\
\hline $30 \&$ more & 9 & 15.0 \\
\hline \multicolumn{3}{|l|}{ 3-Marital status } \\
\hline Single & 12 & 20.0 \\
\hline Married & 48 & 80.0 \\
\hline divorcee & 0 & 0.0 \\
\hline Widower & 0 & 0.0 \\
\hline \multicolumn{3}{|l|}{ 4-Level of education } \\
\hline Diploma in Nursing & 42 & 70.0 \\
\hline Bachelor of Nursing & 9 & 15.0 \\
\hline Technical Institute of Nursing & 9 & 15.0 \\
\hline \multicolumn{3}{|l|}{ 5- Years of experience } \\
\hline$<5$ & 13 & 21.7 \\
\hline $5-10$ & 33 & 55.0 \\
\hline $10 \&$ more & 14 & 23.3 \\
\hline \multicolumn{3}{|c|}{ 6- Attend training courses for cystectomy } \\
\hline Yes & 3 & 5.0 \\
\hline No & 57 & 95.0 \\
\hline
\end{tabular}

Table (2): Distribution of nurses knowledge as regard cystectomy $(n=60)$.

\begin{tabular}{|l|c|c|c|c|}
\hline \multicolumn{1}{|c|}{ Variable } & \multicolumn{2}{c|}{ Yes } & \multicolumn{2}{c|}{ No } \\
\cline { 2 - 5 } & No. & \% & No. & \% \\
\hline Definition of cancer bladder & 48 & 80.0 & 12 & 20 \\
\hline Types of cancer bladder & 23 & 38.3 & 37 & 61.7 \\
\hline Symptoms of cancer bladder & 31 & 51.7 & 29 & 48.3 \\
\hline Indication of cystectomy & 47 & 78.31 & 13 & 21.7 \\
\hline Contraindications to conduct the cystectomy operation & 48 & 80.0 & 12 & 20.0 \\
\hline Potential complications occur for these patients & 50 & 83.3 & 10 & 16.7 \\
\hline
\end{tabular}

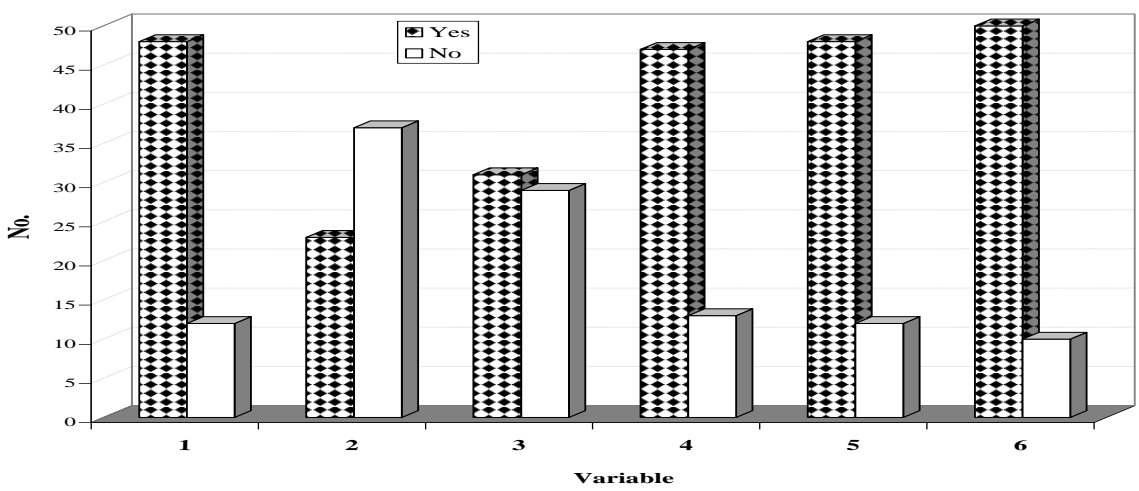

Figure (1): Level of knowledge for nurses about cystectomy $(n=60)$. 
Table (3): Level of practice for nurses in study about cystectomy \& nursing care standards $(n=60)$.

\begin{tabular}{|l|c|c|c|c|}
\hline \multicolumn{1}{|c|}{ Variable } & \multicolumn{2}{c|}{ Yes } & \multicolumn{2}{c|}{ No } \\
\cline { 2 - 4 } & No. & \% & No. & \% \\
\hline Primary nursing care given to patients before cystectomy & 43 & 71.7 & 17 & 28.3 \\
\hline Nnursing cares given to patients after cystectomy. & 40 & 66.7 & 20 & 33.4 \\
\hline The position for patients immediately after operation. & 48 & 80.0 & 12 & 20.0 \\
\hline Measuring vital signs immediately operation for patients & 31 & 51.7 & 29 & 48.3 \\
\hline Observed the wound & 48 & 80.0 & 12 & 20.0 \\
\hline 6-Observe Bleeding for wound. & 46 & 76.7 & 14 & 23.4 \\
\hline The basic daily nursing care and observations for cystectomy patient & 41 & 68.3 & 19 & 31.7 \\
\hline Nursing care of the pain after the operation & 42 & 70.0 & 18 & 30.0 \\
\hline Use the abdomen belt & 42 & 70.0 & 18 & 30.0 \\
\hline Deep breathing exercises and cough after operation & 48 & 80.0 & 12 & 20.0 \\
\hline Nursing care for stoma. & 41 & 68.3 & 19 & 31.7 \\
\hline The precautions must be met to avoid infection of wound & 41 & 68.3 & 19 & 31.7 \\
\hline Symptoms and signs of infected wound & 40 & 66.7 & 20 & 33.4 \\
\hline Instruction that must be given to patients before discharge. & 43 & 71.7 & 17 & 28.3 \\
\hline
\end{tabular}

Table (1): shows that; majority of nurses are female $(86.7 \%)$. More than half of nurses their age ranged from $20>30$ years $(71.7 \%)$ and had diploma of nursing $(70.0 \%)$. Majority of nurses are married $(80.0 \%)$ and no had attended training programs $(80.0 \%, 95.0 \%$ respectively).More than two third of nurses $(55.0 \%)$ years of experience from 5-10 years.

Table (2): cleared that; more than two third of nurses had correct answer for knowledge about definition of bladder cancer, indication of cystectomy, contraindications the cystectomy operation and complications occur for these patients $(80 \%, 78.31 \%$, $80 \%, 83.3 \%$ respectively) but less than two third of nurses done incorrect answer for knowledge about types of cancer bladder (61.7\%).and half of nurses had correct for knowledge about symptoms of cancer bladder $(51.7 \%)$.

Table (3): show that; majority of nurses had correct answer and equal for information about position for patient's immediately after operation, deep breathing exercises and cough after operation and observed the wound $(80.0 \%)$. More than two third of nurses and equal had correct answer for information about nursing care of pain and use of the abdominal belt $(70.0 \%)$. Also the table show that; about half of nurse had correct answer for information about measuring vital signs immediately operation (51.7\%).

\section{Discussion}

Based on the results of the present study, the majority of the nurses are female, more than half their ages ranged from $20>30$ years and have diploma of nursing. The majority of them are married and no hade attended training courses related to cystectomy but more than two third of them their experiences range from 5 to 10 years. This finding in the line with study by Abd Al-Magid, (2011) reported the majority of nurses aged from 20-40 years, female, have diploma in nursing and their experience more than 3 years. Also the result supported by Ahmed (2011), Bessie \& Carol, (2009) stated that education and training are two components of staff development that occur after an employees' indoctrination (which refers to planned, guided adjustment of employee to the organization and work environment). The staffs' knowledge level and capabilities are a major factor in determining the number of staff required to carry out unit goals. The better trained and more competent the staff, the fewer staff required, which in turn saves the organization money and rise reproductively.

The findings revealed that total knowledge regarding nursing care standards of urostomy was at unsatisfactory level. The reasons might be due to the background of the sample. The majority of the nurses had gained a diploma in nursing (70.0\%). Only $(15.5 \%)$ of nurses with Bachelor of Science in Nursing and $(15.0 \%)$ of nurses with Technical Institute in Nursing. Previous study found that education has a significant impact on the knowledge and competencies of the nurse clinician, as it does for all health care providers. Nurses with Bachelor of Science in Nursing (BSN) degrees and Technical Institute in Nursing are well-prepared to meet the demands placed on today's nurse. BSN nurses are prized for their skills in critical thinking, leadership, case management, and health promotion, and for their ability to practice across a variety of inpatient and outpatient settings (Robert, 2012).

This result may be attributed to insufficient courses related to cystectomy included in their undergraduate 
curriculum of nursing education. Most nurses stated that their knowledge gained while working with patients. Also there is no Arabic source for updating and continuing their education. So BSN nurses have important aid to education of other nurses to improve their knowledge.

This result contradicted with Xyrichis, (2007) who stated that multi professional education within tissue viability is vital if patients are to receive optimum care and this education should commence at undergraduate level. However, after qualifying, time pressures within healthcare areas can prove to be a barrier for staff wishing to access courses. Staff often rely on advice from peers who may themselves not have accessed the most up-to-date information which can prevent development of evidence based interventions.

Based on the present study, the majority of nurses answered correct and equal for information as regarding about position for patient's immediately after operation, deep breathing exercises and cough after operation and observed the wound. More than two third of nurses and equal had correct answer for information about nursing care of pain and use of the abdominal belt and about half of nurse had correct answer for information about measuring vital signs immediately after operation.

This result disagree with Cooks, (2011) stated that the nurse is responsible and accountable for the quality of nursing care given to patients. The single most important protective strategy for the nurse is to be a knowledgeable and safe practitioner of nursing and to meet the standards of care with all patients. Nurses are empowered by the SOC and the trust of the physician and the patient to ensure quality care.

\section{Conclusions}

Based on the result of the present study, it can be concluded that, Nurses` knowledge regarding cancer bladder and practice regarding standard nursing care of patient post cystectomy in surgical oncology department of South Egypt Cancer Institute are at an unsatisfactory, inadequate level and need nursing care standards to improve nurses' knowledge and practice. It can be also concluded that the most important topics of the patients' needs are the need for information about operation, nursing tasks the nurse should perform, helping in activities of daily living, and health education and are in agreement with the proposed nursing care standards.

\section{Recommendations}

Based on the finding of this study, following recommendations were made:

\section{For nurses}

- Continuous education and in-service training programs should be conducted at surgical oncology department to improve nurses' knowledge and practice.

- Nurses should be encouraged to read textbooks, periodicals and to attend scientific meeting and conferences.

\section{For patients}

- Patients should be provided with sufficient information on operation and full health education before discharge from the hospital and performing nursing tasks and helping in activities of daily living for the patient to meet their needs.

\section{For further and research}

- Another study should be done to evaluate the effect of implementing nursing care standards for patient post cystectomy in surgical oncology department at South Egypt Cancer Institute on their health status.

- Similar studies on a larger sample acquired from different geographical areas in Egypt should be done to achieve more generalizable results.

- Effect of insufficient nursing care standards for cystectomy patient on their results but come at South Egypt Cancer Institute.

\section{References}

1. Abd Al-Mageed, A., (2011): Nursing care standards for cancer patients undergoing chemotherapy, Submitted for partial fulfillment of the requirements of Doctorate Degree in Adult Nursing, Faculty of Nursing, Assiut University, discussion part,pp.112-115.

2. Ahmed, R., (2011): Developing Postoperative care standards for patients who had drainage of chronic subdural hematoma, thesis submitted for partial fulfillment of the requirements of the master degree in adult nursing, Faculty of nursing, Assiut University, Discussion part, p. 102 .

3. American Cancer Society, (2014): Bladder cancer. Available online: http://www.cancer.org/cancer/bladder cancer/detailed guide/index.

4. Berglund R., \& Herr H., (2012): Surgery of bladder cancer. Campbell Walsh Urology, Philadelphia: Saunders 10th (ed) vol. (3) pp: 2375-2385.

5. Cooks D., (2010): DSHS Nursing Standards of Care and Nursing Standards of Professional Performance $\mathrm{p} 1$.

6. McMahon D., (2011): HG.Org World Wide Legal Directories.HGExperts.com

7. Kaufman D., Shipley W., \& Feldman A., (2009): Bladder cancer. Evidence-based nursing 
guide to disease management, 4st(ed), Lippincott Williams, wilkins, Pp. 320.

8. Kluwer, W., (2009): Evidence-based nursing guide to disease management, 1 st edition, Lippincott Williams\&Wilkins, p.158-162.

9. Bessie M., \& Carol H., (2009): Leader ship roles \& management functions in nursing, 6 ed, Lippincott, Hong Kong P. 371

10. McMahon, D., (2011): Nursing standards of practice, HG experts.com, http://www.hgexperts.com/article.

11. Mohanty N., (2007): Cancer Urinary Bladder Etipathologyits Management, health administrator Vol: XVII, Number 2: Pp. 130131.

12. Mostafa, N., (2012): Developing standards of post-operative nursing interventions for lower limb amputated patients Submitted for Partial Fulfillment of the Requirements of The Master Degree in Adult Nursing (Medical - Surgical Nursing), Faculty of Nursing, Assiut University, discussion part, pp.75-78.

13. Osborn, K., Wraa, C., \& Watson, A., (2010): Medical Surgical Nursing: Preparation for practice, 1 st ed. Chapter 40, Pearson, P 1211.

14. Potter et al., (2006): Canadian Fundamentals of nursing $3^{\text {rd }}$ ed , Elsevier Canada, p 1393.

15. South Egypt Cancer Institute statistics records; (2013-2014).

16. Thomson, (2011): Colostomy Care, United Ostomy Associations of America, Inc, http: //www.drugs.com/cg/colostomy-care.html.

17. Xyrichis A., Lowton K., (2007): what fosters or prevents interprofessional team working in primary \& community care? A literature review. 